\title{
On the persistence of UK inflation: A long-range dependence approach
}

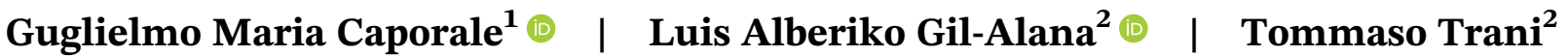

\author{
${ }^{1}$ Department of Economics and Finance, \\ Brunel University London, London, UK \\ ${ }^{2}$ Faculty of Economics, University of \\ Navarra, Pamplona, Spain

\section{Correspondence} \\ *Guglielmo Maria Caporale, Department \\ of Economics and Finance, Brunel \\ University, London, UB8 3PH, UK. \\ Email: guglielmo-maria.caporale@brunel. \\ ac.uk
}

\begin{abstract}
This paper examines the degree of persistence in UK inflation by applying long-memory methods to historical data that span the period from 1660 to 2016. Specifically, we use both parametric and non-parametric fractional integration techniques, that are more general than those based on the classical I (0) vs. I(1) dichotomy. Further, we carry out break tests to detect any shifts in the degree of persistence, and also run rolling-window and recursive regressions to investigate its evolution over time. On the whole, the evidence suggests that the degree of persistence of UK inflation has been relatively stable following the Bretton Woods period, despite the adoption of different monetary regimes. The estimation of an unobserved-components stochastic volatility model sheds further light on the issues of interest by showing that post-Bretton Woods changes in UK inflation are attributable to a fall in the volatility of permanent shocks. The same type of analysis carried out for US inflation, for comparison purposes, leads to broadly similar conclusions.
\end{abstract}

\section{KE Y W O R D S}

fractional integration, persistence, UK inflation

\section{1 | INTRODUCTION}

Inflation persistence has been extensively analysed in the literature because its properties have implications for both theoretical models and monetary policy. Central banks aim to anchor expectations in order to lower persistence and reduce the output costs of disinflation (Moreno \& Villar, 2010), since high persistence is often due to backward-looking expectations in the presence of price and wage rigidities (Gali \& Gertler, 1999). Alternatively, it might reflect the fact that private agents have limited information about the objectives of the central bank, which underlines the importance of transparency for monetary policy (Walsh, 2007).
After World War II (WWII), the degree of inflation persistence has been high in several countries (Miles, Panizza, Reis, \& Ubide, 2017), but there has been controversy over whether it has remained stable throughout the post-WWII period. Empirical tests based on autoregressive (AR) models, namely the approach most frequently used in the literature, suggest that it may have decreased when central banks started to follow inflationtargeting policies. However, studies based on such models usually find it difficult to reject the hypothesis that inflation has a unit root. Moreover, according to Pivetta and Reis (2007) and Stock and Watson (2007, 2010), no significant change in persistence can be detected over the post-WWII period if one accounts for 
uncertainty around point estimates or distinguishes between persistent and transitory changes in inflation.

The aim of the present paper is to provide further evidence on the stochastic behaviour of inflation by using long-memory (fractional integration) techniques to analyse the UK experience. The historical data for inflation in this country span a much longer time period than those for others, and therefore the UK experience is particularly suitable to examine persistence with longmemory methods; in particular, our sample includes more than 350 annual observations, from the Restoration of the English monarchy in the second half of the 17th century until 2016. The advantage of using these methods is that they do not require imposing the assumption of a unit root or a simple AR process, and therefore are much more general and flexible than the AutoRegressiveMoving Average (AR[I]MA) models most commonly used in the literature. In addition, in order to examine any possible changes in persistence, we also test for breaks and estimate persistence in the corresponding subsamples, and then we apply rolling-window and recursive methods to capture other forms of time variation. Finally, with the aim of shedding further light on our findings for the post-WWII period (during which inflation dynamics have been a source of controversy) we estimate the Unobserved-Components Stochastic Volatility Outlier-adjusted (UCSVO) model of Stock and Watson (2016). The chosen fractional integration framework already represents an improvement relative to AR(I)MA modelling, and the UCSVO model also enables us to interpret the evidence in terms of permanent or transitory changes in inflation. For comparison purposes, we estimate this model for US inflation as well.

The layout of the remainder of the paper is as follows. Section 2 reviews the literature, Section 3 outlines the methodology, Section 4 describes the data, and Section 5 discusses the results. Finally, Section 6 offers some concluding remarks.

\section{2 | LITERATURE REVIEW}

The period following WWII has been characterized in many countries by high persistence (Miles et al., 2017). Theorists have followed two main approaches to explain this stylized fact (Meenagh, Minford, Nowell, Sofat, \& Srinivasan, 2009). In New Keynesian DSGE models (e.g., Christiano, Eichenbaum, \& Evans, 2005) persistence is directly related to the specification of the Phillips curve and is not affected by changes in monetary regime. By contrast, on the basis of the Lucas (1976) critique one would expect economic agents to revise their decision rules in response to policy changes and therefore the reduced-form parameters of structural DSGE models, including inflation persistence, to change over time. Meenagh et al. (2009) report evidence confirming that persistence varies across regimes and conclude that models with little nominal rigidity are the most suitable to account for its behaviour. Dixon and Kara (2006) argue that the distribution of contract lengths explains inflation persistence better than indexation. Model-based indexation mechanisms have indeed received several criticisms for being ad hoc (Cogley \& Sbordone, 2005) or not sufficiently justified on both empirical and theoretical grounds (Woodford, 2007).

Numerous empirical studies have analysed inflation persistence using different approaches, but mainly estimating ARMA models. Well-known contributions are those of Backus and Zin (1993), Hassler and Wolters (1995), Baum, Barkoulas, and Caglayan (1999), Marques (2004), Altissimo, Ehrmann, and Smets (2006), Okimoto and Kumar (2007), Caporin and Gupta (2017) and Rinke, Busch, and Leschinski (2017). Papers on US inflation initially focused on point estimates, and found that inflation persistence had declined after the 1980s (Cogley \& Sargent, 2002). ${ }^{1}$ However, subsequent studies allowing for uncertainty around point estimates concluded that it had remained stable (Pivetta \& Reis, 2007). More recently, Stock and Watson $(2007,2010)$ have suggested a method to separate transitory and permanent components of inflation and reconcile the previous two findings. Stock and Watson (2016) refined this method further by including a model-based adjustment for large inflationary spikes (i.e., outliers). ${ }^{2}$

As for UK inflation in particular, some studies have focused on non-linearities (Arghyrou, Martin, \& Milas, 2005; Clements \& Sensier, 2003), while others have analysed its behaviour under different monetary regimes (e.g., Nelson, 2001, 2009 and Nelson \& Nikolov, 2004). Benati (2008) examined inflation both in the UK (from 1750 to 2003) and in other countries in order to understand whether inflation persistence could be deemed structural in the sense of Lucas (1976). His results, based on both reduced-form (sum of AR coefficients) and structural regressions (New Keynesian models estimated with Bayesian methods), do not support a structural interpretation of persistence. ${ }^{3}$ Miles and Vijverberg (2011) estimated a Markov-switching model and found that inflation targeting in the UK reduced inflation uncertainty. Balke and Fomby (1997) argue in favour of threshold cointegration models to capture non-linearities.

The issue of seasonality is addressed by Osborn and Sensier (2009), who find that both seasonal patterns and persistence in (monthly) UK inflation have changed over time; specifically, both a univariate model and a Phillips 
curve representation of UK inflation suggest the presence of a structural break that can be associated with the introduction of inflation targeting in October 1992; the reduction of inflation persistence after 1993 is seen as an indication of the success of the Bank of England's monetary policy.

As reported by Miles et al. (2017), UK inflation has behaved rather similarly to US inflation over the time period for which data are available for both countries, namely since the beginning of World War I (WWI). Specifically, both their level and volatility were initially rather high, but went down over time, especially during the Great Moderation (i.e., in the 1990s). Inflation volatility then increased again during the Great Recession brought about by the global financial crisis of 2007-8, when it reached values similar to those of the Great Depression of 1929.

\section{3 | ECONOMETRIC METHODOLOGY}

Our analysis is closely related to Benati's (2008) one, but we consider a slightly longer time series and carry out a different set of reduced-form tests. Specifically, we estimate the following model:

$$
y_{t}=\alpha+\beta t+x_{t},(1-L)^{d} x_{t}=u_{t}, t=1,2, \ldots, T,
$$

where $y_{t}$ stands for the rate of inflation, $\alpha$ and $\beta$ are unknown coefficients corresponding respectively to the intercept and a linear time trend, the de-trended series $x_{t}$ and the error $u_{t}$ are assumed to be $\mathrm{I}(d)$ and $\mathrm{I}(0)$ respectively, and $d$ is an unknown parameter, to be estimated together with $\alpha$ and $\beta$.

We examine the cases of both uncorrelated (white noise) and auto-correlated (Bloomfield, 1973) errors, ${ }^{4}$ and estimate three different specifications of the model: i) without deterministic terms, setting $\alpha=\beta=0$ a priori, in Equation (1); ii) with an intercept, that is, with $\alpha$ being unknown and $\beta=0$ a priori; and iii) with a linear time trend, with $\alpha$ and $\beta$ in Equation (1) both being unknown.

Regardless of the case considered, the model in Equation (1) implies that $y_{t}$ is stationary only if $d<0.5$; otherwise, that is, for $d \geq 0.5$, it is not covariancestationary and is highly persistent. ${ }^{5}$ In the latter case, $y_{t}$ can either be mean reverting (i.e., $d<1$ ) or not. Therefore, since $d$ is a real-value parameter, one can assess the degree of persistence of inflation with more accuracy than by using the competing $\mathrm{AR}(\mathrm{I})(\mathrm{MA})$ models, which have been frequently employed in the literature. In particular, the estimation of $d$ enables one to distinguish between unit root and near-unit root processes. We use the parametric procedure of Robinson (1994) that yields Whittle estimates of $d$ in the frequency domain (Dahlhaus, 1989), using the non-parametric approach of Bloomfield (1973) when allowing for autocorrelation in the error term. ${ }^{6}$ Bloomfield (1973) showed that the log of the spectral density function of an $\mathrm{AR}(\mathrm{p})$ process can be fairly well approximated by the $\log$ of the following function:

$$
f\left(\lambda ; \sigma^{2}\right)=\frac{\sigma^{2}}{2 \pi} \exp \left(2 \sum_{r=1}^{m} \tau_{r} \cos (\lambda r)\right),
$$

where $\sigma^{2}$ is the variance of the error term and $m$ indicates the last of the Fourier frequencies which is associated with the short-run parameters. This model has also the advantage that it is stationary for all values unlike the AR case, but produces autocorrelations decaying at an exponential rate as in that case.

After obtaining these two sets of results for the whole sample period, we estimate $d$ using a rolling-window approach to detect any change in the (fractional) degree of integration and, therefore, any possible time variation in the persistence of inflation. In order to obtain reliable estimates, the window width is chosen to be 60 years. In addition, we also estimate $d$ with a recursive approach, starting with a sample of 60 observations, and adding recursively one more at a time. The possibility of structural breaks in the same fractional integration context is also investigated.

Finally, to gain additional insights into our results for the last part of the sample period (i.e., the post-WWI subsample), we estimate a UCSVO model. When trying to assess the (in)stability of inflation persistence, the literature has mostly focused on the post-WWI period; the UCSVO framework enables one to analyse that issue in terms of permanent and transitory changes in inflation. In particular, the assumption behind the UCSVO model is that inflation can be decomposed into (i) a trend component following a martingale process and (ii) transitory shocks. Both the permanent shocks affecting the trend and the transitory ones are assumed to have a timevarying variance; a correction for outliers is also used in the case of the latter, which is useful to reduce the probability of a single large shock being taken as a signal of a more systematic increase in the volatility of transitory shocks.

The UCSVO model is estimated with Bayesian methods, with the posterior distribution of the variables of interest being obtained using a Markov Chain Monte Carlo (MCMC) algorithm. In particular, we use the algorithm proposed by Stock and Watson (2016), which 
improves the accuracy of the estimates for two reasons. First, the posterior distributions of the stochastic volatilities are approximated with an accurate 10-component Gaussian mixture (Omori, Chib, Shephard, \& Nakajima, 2007). Second, the algorithm is devised to avoid the general mistake found in the implementation of models with stochastic volatility by Del Negro and Primiceri (2015). Moreover, the framework of Stock and Watson (2016) is particularly suitable for our purposes, since it was developed to fit post-WWII US data, which exhibit several similarities with the UK inflation ones over the same period (Miles et al., 2017)—we compare the two series in Section 5.2.2. Appendix B provides details of both the UCSVO model (Section B1) and its estimation (Section B2).

\section{4 | DATA DESCRIPTION}

The series examined is annual headline CPI inflation; the source is the Bank of England's historical macroeconomic dataset. ${ }^{7}$ Following Miles et al. (2017), we start our analysis in 1660 , which is the year of the Restoration of the British monarchy and precedes by a few decades the de facto adoption of the Gold Standard monetary regime in 1717. Therefore, our sample period goes from 1660 to 2016.

Figure 1 displays the series under investigation. Visual inspection suggests that UK inflation was highly volatile around zero and not very persistent until approximately the start of the 20th century; both its level and degree of persistence have instead been higher since the official end of the Gold Standard (i.e., 1914).

In order to obtain a clearer picture of how the level and volatility of inflation evolved over time, we report in Table 1 summary statistics for six subsamples. These are: the period preceding the de jure Gold Standard, the de jure Gold Standard, the interwar period, the Bretton Woods regime, the interim regime between the Bretton Woods system and the adoption of inflation targeting by the Bank of England, and the inflation targeting regime.
The table shows that inflation was generally low and volatile during the first three periods, with the interwar period being deflationary. Moreover, it declined over time until the Bretton Woods period, during which its volatility kept falling while inflation itself was generally higher than previously. After the end of the Bretton Woods system inflation volatility rose even further, until the adoption of inflation targeting by the Bank of England reduced both its level and volatility, with inflation stabilizing around $2 \%$.

Figure 2 reports some preliminary evidence on inflation persistence based on standard measures used in the existing literature, namely the Pearson statistic (which focuses on adjacent observations) and the first-order autocorrelation coefficient in an OLS regression, applying both rolling and recursive-window methods. The results are almost identical for both methods and suggest that inflation persistence was generally not significantly different from zero until approximately 1850 . Subsequently, and most notably after WWI, persistence jumped and then reached a plateau. It is noteworthy that, while the rolling-window estimates suggest that it increased slightly also over the last part of our sample (i.e., during the Great Moderation and after 2000), the recursivewindow ones imply that the last upward correction in the post-WWI era occurred in the 1980s.

\section{5 | EMPIRICAL RESULTS}

\section{1 | Fractional integration analysis}

Table 2 reports the estimates of $d$ under the assumption of uncorrelated and auto-correlated errors, respectively, for the three models previously mentioned. The other estimated coefficients are shown in Table 3. The results indicate that a time trend is required regardless of the specification adopted for the error term. Under the assumption of white noise residuals, the estimated value of $d$ is 0.22 , which is significantly higher than 0 and implies long-memory behaviour. By contrast, when

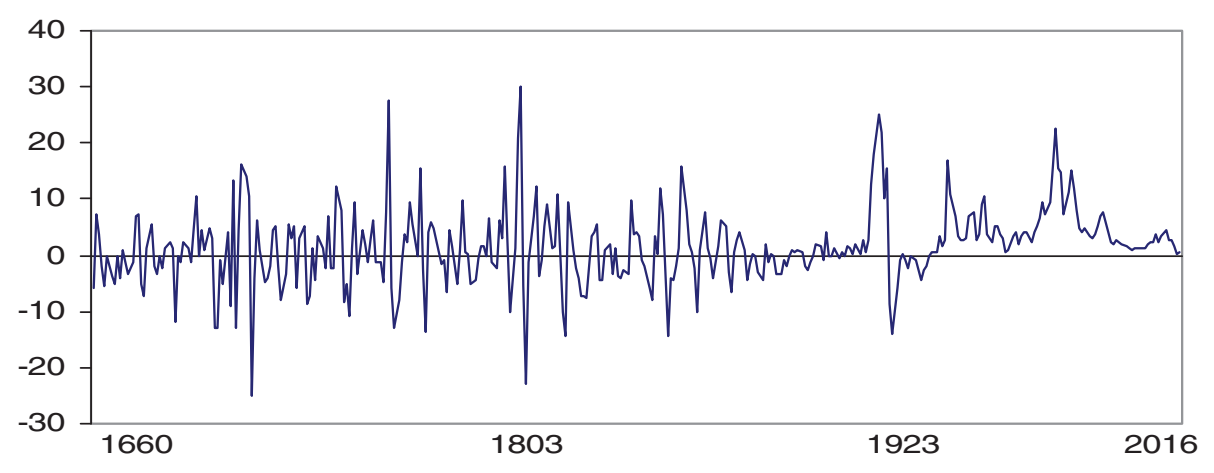

F I G URE 1 UK inflation rate (1660-2016) [Colour figure can be viewed at wileyonlinelibrary.com] 
T A B L E 1 Historical summary statistics

\begin{tabular}{|lllllll} 
& $\begin{array}{l}\text { “Pre-de jure" Gold } \\
\text { Standard: }\end{array}$ & $\begin{array}{l}\text { “De jure” Gold } \\
\text { Standard: }\end{array}$ & $\begin{array}{l}\text { Interward } \\
\text { period }\end{array}$ & $\begin{array}{l}\text { Bretton } \\
\text { woods }\end{array}$ & $\begin{array}{l}\text { Bretton woods to } \\
\text { inflation targeting }\end{array}$ & $\begin{array}{l}\text { Inflation } \\
\text { targeting }\end{array}$ \\
\hline Mean & 0.55 & 0.03 & -1.89 & 4.37 & 9.18 & 2.09 \\
Median & 0.39 & 0.20 & -0.80 & 3.88 & 7.50 & 2.06 \\
\hline Min & -25.19 & -14.40 & -14.00 & 0.60 & 3.20 & 0.04 \\
Max & 30.02 & 15.66 & 3.40 & 10.65 & 22.70 & 4.46 \\
SD & 7.60 & 4.36 & 4.12 & 2.49 & 5.33 & 1.07 \\
\hline
\end{tabular}

Note: The entries are expressed as percentages. The historical breakdown is as follows: pre-"de jure” Gold Standard from 1660 to 1820 , "de jure" Gold Standard from 1821 to 1914, interwar period from 1921 to 1939, Bretton Woods from 1944 to 1971, Bretton Woods to inflation targeting from 1972 to 1991, inflation targeting from 1992 onwards.
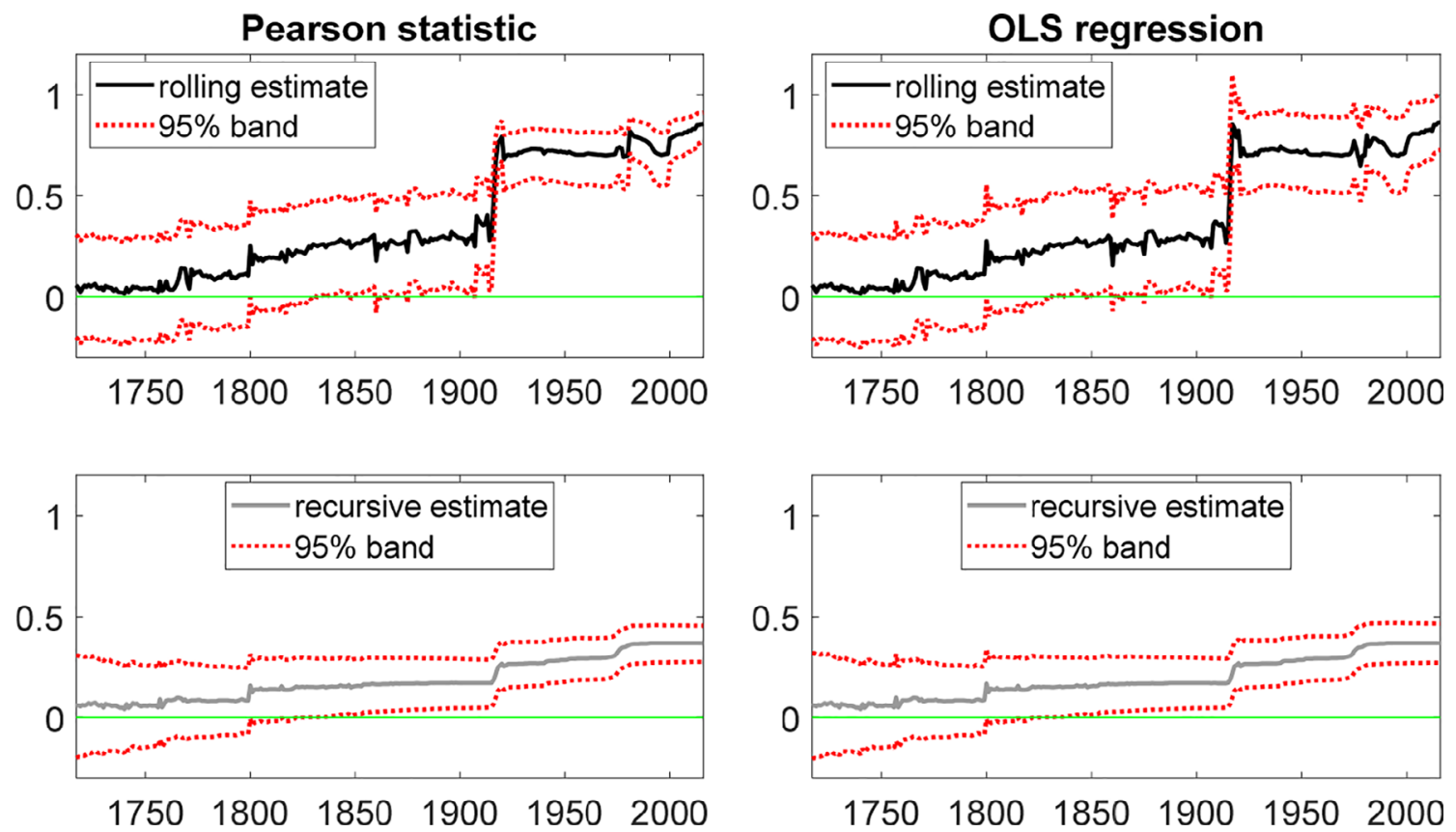

F I G U R E 2 Rolling and recursive first-order autocorrelation coefficients [Colour figure can be viewed at wileyonlinelibrary.com]

T A B L E 2 Estimates of $d$ for the UK inflation rate

TABLE 3 Estimated coefficients for the UK inflation rate (preferred model)

\begin{tabular}{|llll|}
\hline & No regressors & An intercept & A linear time trend \\
\hline White noise & $0.24(0.16,0.36)$ & $0.25(0.17,0.35)$ & $\mathbf{0 . 2 2}(\mathbf{0 . 1 3}, \mathbf{0 . 3 5})$ \\
\hline Bloomfield & $0.02(-0.04,0.09)$ & $0.02(-0.04,0.10)$ & $\mathbf{- 0 . 0 8}(\mathbf{- 0 . 1 6 , 0 . 0 2})$ \\
\hline
\end{tabular}

Note: In bold, the significant results according to the deterministic terms.

\begin{tabular}{|llll|} 
& $\boldsymbol{d}$ & Intercept coeff. & Time trend coeff. \\
\hline White noise & $0.22(0.13,0.35)$ & $-0.96071(-2.56)$ & $0.01405(1.77)$ \\
\hline Bloomfield & $-0.08(-0.16,0.02)$ & $-1.10705(-2.41)$ & $0.01482(6.49)$ \\
\hline
\end{tabular}




\begin{tabular}{|llll}
\hline \multicolumn{2}{l}{ Panel A: White noise errors } \\
\hline & No regressors & An intercept & A linear time trend \\
\hline$(1660-1933)$ & $0.12(0.00,0.29)$ & $\mathbf{0 . 1 2}(\mathbf{0 . 0 0}, \mathbf{0 . 2 9})$ & $0.12(-0.01,0.29)$ \\
\hline$(1934-2016)$ & $0.74(0.57,1.00)$ & $\mathbf{0 . 7 3}(\mathbf{0 . 5 7}, \mathbf{1 . 0 0})>$ & $0.73(0.56,1.00)$ \\
\hline Panel B: Auto-correlated errors & & \\
\hline & No regressors & An intercept & A linear time trend \\
\hline$(1660-1933)$ & $-0.27(-0.35,-0.16)$ & $\mathbf{- 0 . 2 9}(-\mathbf{0 . 3 9}, \mathbf{- 0 . 1 5})$ & $-0.32(-0.42,-0.18)$ \\
\hline$(1934-2016)$ & $0.37(0.13,0.65)$ & $\mathbf{0 . 3 4}(\mathbf{0 . 1 3}, \mathbf{0 . 6 5})$ & $0.34(0.11,0.65)$ \\
\hline
\end{tabular}

Note: In bold, the significant results on the basis of the deterministic terms.
T A B L E 4 Estimated coefficients for the UK inflation rate assuming that the error term $u_{t}$ is auto-correlated as in the exponential spectral model of Bloomfield (1973), the estimated value of $d$ is approximately equal to -0.08 and the $\mathrm{I}(0)$ null hypothesis (short memory) cannot be rejected, namely a lower degree of persistence is found in this case. ${ }^{8}$

In the Appendix, Figure A1 shows a slightly upward trend for both uncorrelated (in Figure A1i) and autocorrelated errors (in Figure A2ii); note, however, that the estimated coefficients (see Table 3) were obtained under the assumption of a constant differencing parameter over the whole sample period.

Next we examine the possibility of structural breaks. For this purpose, we use first the Bai and Perron (2003) approach, and then the methods proposed by GilAlana (2008) and Hassler and Meller (2014), both specifically designed for the case of fractional integration. These methods are based on minimizing the sum of squared residuals over different subsamples. The results in all three cases indicate that there is a single break in the series around 1933. Therefore, we split the sample into the two corresponding subsamples, and estimate the differencing parameter for each of them. The results are displayed in Table 4. There appears to be a very significant increase in the degree of persistence after the break. In particular, under the white noise assumption for the error term, the estimated value of $d$ increases from 0.12 in the first subsample to 0.73 in the second one. When allowing for autocorrelation in the disturbances, the estimates are much smaller, but there is once again an increase from 0.29 in the first subsample to 0.34 in the second one. Note that these results provide evidence of long memory $(d>0)$ in the second subsample, regardless of the assumption made about the error term.

Even when allowing for breaks, the model still imposes a constant parameter for the degree of integration in each subsample with a sudden break around 1933. Next, we investigate if the differencing parameter has remained stable or not over the whole sample as well as the subsamples considered. In Figure 3, we display the 60-year rolling-window estimates of $d$, once again for the two cases of uncorrelated and auto-correlated errors. ${ }^{9}$ The results are broadly consistent; the lower values in the latter case might be due to the competition between the differencing parameter and the Bloomfield one in describing the degree of dependence. As can be seen, inflation persistence was rather stable from 1660 to approximately 1776 . Then, there was a slight increase until 1917-18, followed by a sharp jump to a stable higher level, and a further slight increase from 1981.

Given the results in Figure 3, we use once again GilAlana's (2008) approach to test for breaks in the series corresponding to the rolling-window estimates and obtain additional information on the evolution of persistence over time. The results are conclusively in favour of three breaks in these series, specifically, in 1776, 1917 and 1980. Table 5 reports the estimates of $d$ (and their 95\% confidence interval) for the corresponding subsamples.

Table 5, Panels A and B, shows the results for uncorrelated and auto-correlated disturbances, respectively. The degree of persistence appears to have increased monotonically over time. In particular, in the case of uncorrelated errors, the estimated value of $d$ increases from -0.25 in the first subsample to 0.13 in the second, 0.84 in the third and 0.99 in the fourth one, and the $\mathrm{I}(1)$ null hypothesis cannot be rejected in the last two subsamples. With auto-correlated disturbances, the estimate of $d$ is initially equal to -0.89 , and then moves over time to $-0.48,-0.06$ and finally 0.00 ; however, the corresponding confidence intervals are very wide and therefore the differences between the estimated parameters are not statistically significant.

To complete the fractional integration analysis, we reestimate $d$, this time recursively, starting with a sample of 60 observations, (1660-1719) and adding one observation at a time. The estimated values of $d$ (along with their 95\% bands) for the case of uncorrelated errors are displayed in Figure 4(i). The time trend (not shown) becomes significant from the 98th subsample onwards, 
F I G U RE 3 Rolling-window estimates of $d$ with 60 years of observations i) No autocorrelation (white noise)

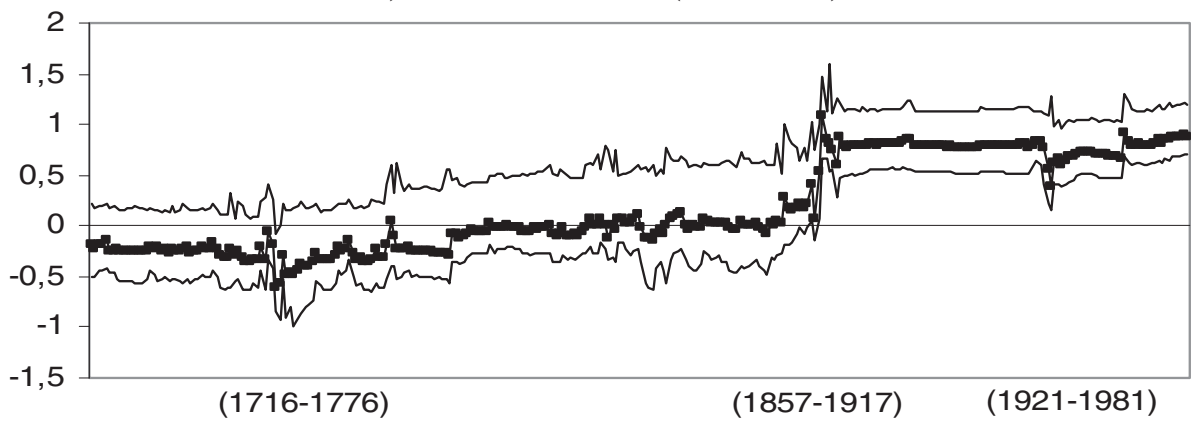

ii) Autocorrelation (Bloomfield)

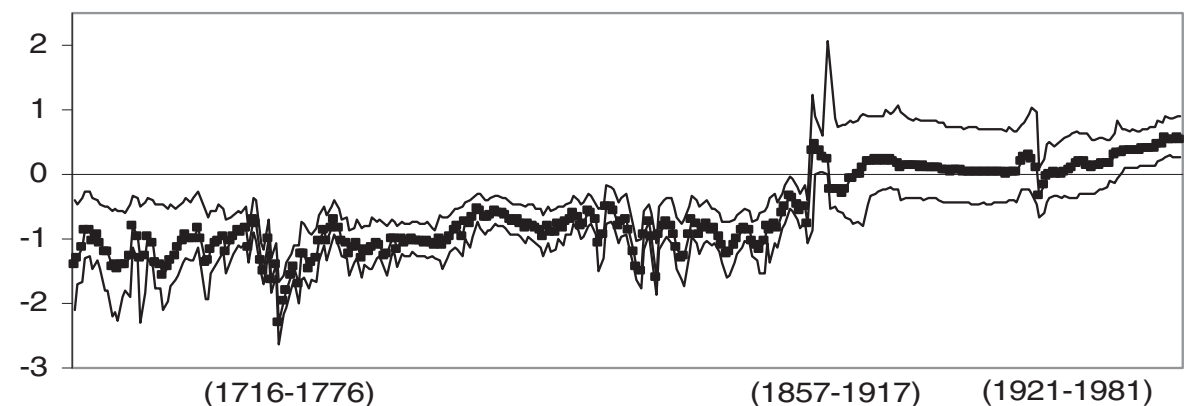

namely from the 1660-1816 subsample onwards. The estimate of $d$ remains around -0.2 from the first subsample till the one incorporating the year 1822; then it jumps, and remains stable (slightly below 0 ) till the subsample ending in 1917. Subsequently it increases once more, and it remains significantly above 0 thereafter. It is noteworthy that the recursive estimates of $d$ are systematically lower than the first-order autocorrelation coefficients displayed in Figure 2, which suggests that standard AR(1) models might overestimate the degree of inflation persistence.

The recursive estimation under the alternative assumption of auto-correlated disturbances yields a similar picture, although the estimated values of $d$ are about 0.20 smaller in all cases (see Figure 4a).

Finally, the Gil-Alana (2008) tests on the recursive estimates of $d$ imply that the break dates are 1822, 1917 and 1975. The estimated values of $d$ for each subsample are reported in Table 6; it can be seen that $d$ increases from the first to the second and then the third subsample, while it remains stable in the last one. In particular, with uncorrelated disturbances, the estimates of $d$ for the four subsamples are $-0.05,0.51,0.77$ and 0.78 , respectively; therefore there is evidence of long memory $(d>0)$ in the last three subsamples. Under the assumption of autocorrelation, the corresponding values are $-0.87,-0.25$, -0.06 and -0.05 , and the $\mathrm{I}(0)$ null hypothesis cannot be rejected for any of the last three subsamples.

To summarize, our results suggest that UK inflation has been highly persistent since the end of WWI. Moreover, the rolling- and recursive-window estimates of the fractional degree of integration $d$ imply that the null hypothesis of a stable degree of persistence since WWI cannot be rejected. The slight increase in inflation persistence detected for the years after the 1980s by the rollingwindow estimation is likely to reflect the fact that this method tends to overestimate the effects of the last regime change detected by the break tests.

\section{2 | UCSVO analysis}

Our findings for the latter part of the sample are consistent with those of Pivetta and Reis (2006) and Stock and Watson $(2007,2010)$ for the US, even though both these studies adopted econometric strategies that differ from ours. In particular, Stock and Watson (2007) proposed analysing trend inflation using an unobservedcomponents stochastic volatility model, which allows for an economically meaningful interpretation of the evolution of inflation in terms of permanent and transitory shocks. In this section, we describe the results obtained applying the most recent version of their model, namely the UCSVO model (Stock \& Watson, 2016), which embeds a correction for outliers. For comparison purposes, we carry out the analysis for US as well as UK inflation.

\subsection{1 | UK inflation results}

We estimate the UCSVO model over two subsamples, namely: (a) 1918-2016 and (b) 1950-2016. The first is 


\begin{tabular}{|c|c|c|c|c|}
\hline \multicolumn{5}{|c|}{ Panel A: White noise errors } \\
\hline Period & Dates & No regressors & An intercept & A linear trend \\
\hline First subsample & $1660-1776$ & $\begin{array}{l}-0.14 \\
(-0.28,0.10)\end{array}$ & $\begin{array}{l}-0.13 \\
(-0.30,0.10)\end{array}$ & $\begin{array}{l}-0.25 \\
(-0.46,0.07)\end{array}$ \\
\hline Second subsample & $1777-1917$ & $\begin{array}{l}0.13 \\
(-0.06,0.47)\end{array}$ & $\begin{array}{l}0.13 \\
(-0.06,0.45)\end{array}$ & $\begin{array}{l}0.13 \\
(-0.07,0.46)\end{array}$ \\
\hline Third subsample & 1918-1980 & $\begin{array}{l}0.63 \\
(0.42,1.00)\end{array}$ & $\begin{array}{l}0.84 \\
(0.55,1.11)\end{array}$ & $\begin{array}{l}0.85 \\
(0.61,1.11)\end{array}$ \\
\hline Fourth subsample & $1981-2016$ & $\begin{array}{l}1.03 \\
(0.57,1.84)\end{array}$ & $\begin{array}{l}0.99 \\
(0.50,1.63)\end{array}$ & $\begin{array}{l}0.99 \\
(0.71,1.84)\end{array}$ \\
\hline \multicolumn{5}{|c|}{ Panel B: Auto-correlated errors } \\
\hline Period & Dates & No regressors & An intercept & A linear trend \\
\hline First subsample & $1660-1776$ & $\begin{array}{l}-0.47 \\
(-0.61,-0.30)\end{array}$ & $\begin{array}{l}-0.49 \\
(-0.63,-0.31)\end{array}$ & $\begin{array}{l}-0.89 \\
(-1.12,-0.63)\end{array}$ \\
\hline Second subsample & $1777-1917$ & $\begin{array}{l}-0.47 \\
(-0.64,0.28)\end{array}$ & $\begin{array}{l}-0.39 \\
(-0.50,0.23)\end{array}$ & $\begin{array}{l}-0.48 \\
(-0.62,0.33)\end{array}$ \\
\hline Third subsample & 1918-1980 & $\begin{array}{l}0.13 \\
(0.06,0.44)\end{array}$ & $\begin{array}{l}0.20 \\
(-0.09,1.08)\end{array}$ & $\begin{array}{l}-0.06 \\
(-0.39,1.09)\end{array}$ \\
\hline Fourth subsample & $1981-2016$ & $\begin{array}{l}-0.47 \\
(-0.97,0.35)\end{array}$ & $\begin{array}{l}-0.13 \\
(-0.42,0.21)\end{array}$ & $\begin{array}{l}0.00 \\
(-0.38,0.95)\end{array}$ \\
\hline
\end{tabular}

Note: In bold, the significant results on the basis of the deterministic terms.

i) No autocorrelation (white noise)

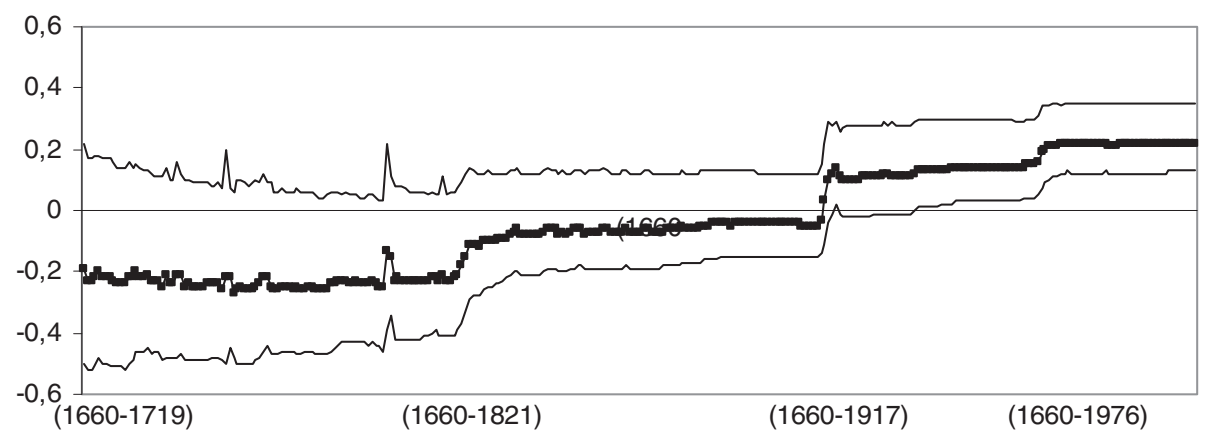

ii) Autocorrelation (Bloomfield)

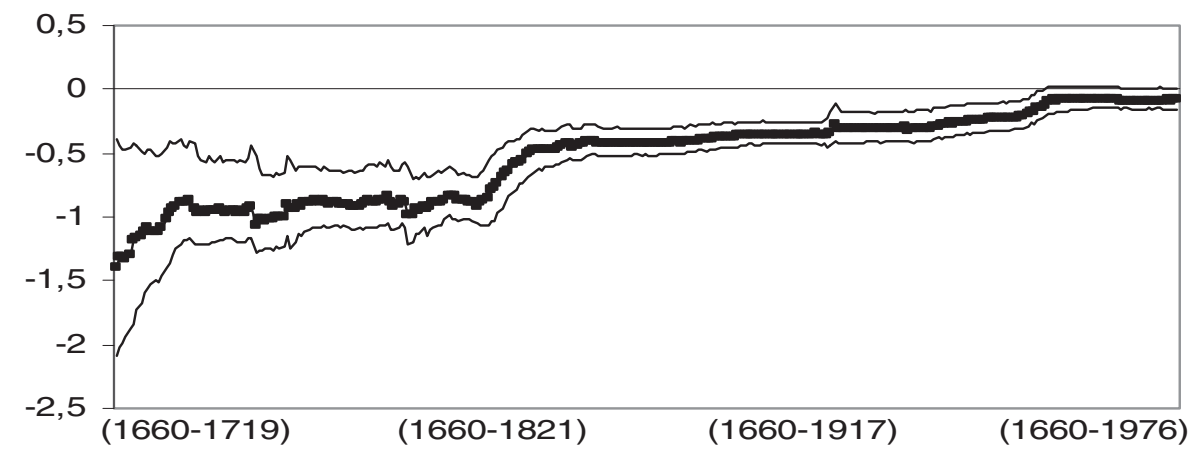

T A B L E 5 Rolling-window estimates of $d$ for each subsample
F I G U RE 4 Recursive estimates of $d$ starting with 60 observations and adding one observation at a time chosen on the basis of the previous empirical analysis: visual inspection of the data (Figure 1) suggests that the biggest change in the behaviour of UK inflation occurred at the end of WWI, and our tests have in fact detected a statistically significant break in 1917 in the context of both the rolling-window and recursive analysis. The choice of the second subsample follows the literature, with most studies examining the period starting around 
1950 when the Bretton Woods system had just been put in place.

Figure 5 shows the results for both subsamples; specifically, it displays the variance of permanent and transitory shocks respectively and also the estimated outliers, which are allowed to occur every 2 years (see Section B3 of the Appendix for the estimated trends and further results). ${ }^{10}$ It appears that the volatility of permanent shocks declined over time, while that of transitory shocks remained constant, regardless of whether the starting point of the estimation is the end of WWI or a few years after the beginning of Bretton Woods. The only slight differences between the results based on the first and second subsample are the narrower confidence bands and slightly smaller median estimate in the case of the latter. The difference in the level is not statistically significant, while the volatility of permanent changes in inflation was very high at the beginning of the 20th century, it remained so in the interwar period and during the 1970s, and then converged towards zero after the 1990s. Finally, in the most recent years (during the Great Recession and its aftermath) UK inflation appears to be driven mainly by outliers, the volatility of transitory shocks remaining essentially the same as in the past.

According to these findings, inflation targeting may have contributed to reducing the effects of permanent shocks from the beginning of the 1980s, while transitory shocks have played a major role as a driving factor. The latter signal changes in relative prices, for example, following commodity price shocks; they typically have negative but short-lived effects on consumption that are often difficult for monetary authorities to control. The main change appears to have been the decline in the volatility of permanent shocks rather than in their persistence, which is consistent with our previous finding that the degree of fractional integration remained more or less the same after 1917. Moreover, the break in UK inflation in the early 1980s detected by our tests is associated with a relatively high volatility of permanent shocks and some large outliers (see Figure 5).

\subsection{2 | US inflation results}

We measure US inflation as the year-on-year change in the headline US CPI index for all urban consumers (US Bureau of Labor Statistics). ${ }^{11}$ This series spans the period 1913-2016 and is therefore shorter than the UK series.

Figure 6 displays both series, and Table 7 reports their average and $S D$ from the interwar period onwards. These summary statistics suggest that UK and US inflation have behaved similarly over time, although at different levels. On average, UK inflation was larger than US inflation during Bretton Woods and the transitory period between the latter and the one characterized by inflation targeting. However, as Figure 6 shows, this difference is mostly associated with
T A B L E 6 Recursive estimates of $d$ for each subsample

\begin{tabular}{|c|c|c|c|c|}
\hline \multicolumn{5}{|c|}{ Panel A: White noise errors } \\
\hline Period & Dates & No regressors & An intercept & A linear trend \\
\hline First subsample & $1660-1822$ & $\begin{array}{l}-0.05 \\
(-0.16,0.15)\end{array}$ & $\begin{array}{l}-0.05 \\
(-0.17,0.16)\end{array}$ & $\begin{array}{l}-0.11 \\
(-0.29,0.14)\end{array}$ \\
\hline Second subsample & 1823-1917 & $\begin{array}{l}0.54 \\
(0.27,0.85)\end{array}$ & $\begin{array}{l}0.51 \\
(0.26,0.81)\end{array}$ & $\begin{array}{l}0.53 \\
(0.30,0.82)\end{array}$ \\
\hline Third subsample & 1918-1975 & $\begin{array}{l}0.70 \\
(0.45,1.04)\end{array}$ & $\begin{array}{l}0.77 \\
(0.50,1.07)\end{array}$ & $\begin{array}{l}0.77 \\
(0.48,1.07)\end{array}$ \\
\hline Fourth subsample & 1976-2016 & $\begin{array}{l}0.71 \\
(0.49,1.13)\end{array}$ & $\begin{array}{l}0.60 \\
(0.40,1.18)\end{array}$ & $\begin{array}{l}0.78 \\
(0.54,1.16)\end{array}$ \\
\hline \multicolumn{5}{|c|}{ Panel B: Auto-correlated errors } \\
\hline Period & Dates & No regressors & An intercept & A linear trend \\
\hline First subsample & $1660-1822$ & $\begin{array}{l}-0.32 \\
(-0.40,-0.22)\end{array}$ & $\begin{array}{l}-0.37 \\
(-0.45,-0.25)\end{array}$ & $\begin{array}{l}-0.87 \\
(-1.04,-0.57)\end{array}$ \\
\hline Second subsample & 1823-1917 & $\begin{array}{l}-0.40 \\
(-0.93,0.37)\end{array}$ & $\begin{array}{l}-0.34 \\
(-0.74,0.33)\end{array}$ & $\begin{array}{l}-0.25 \\
(-0.69,0.40)\end{array}$ \\
\hline Third subsample & 1918-1975 & $\begin{array}{l}0.12 \\
(-0.28,0.70)\end{array}$ & $\begin{array}{l}0.13 \\
(-0.32,0.76)\end{array}$ & $\begin{array}{l}-0.06 \\
(-0.49,0.75)\end{array}$ \\
\hline Fourth subsample & 1976-2016 & $\begin{array}{l}-0.04 \\
(-0.38,0.49)\end{array}$ & $\begin{array}{l}-0.02 \\
(-0.31,0.32)\end{array}$ & $\begin{array}{l}-0.05 \\
(-0.32,0.59)\end{array}$ \\
\hline
\end{tabular}

Note: In bold, the significant results on the basis of the deterministic terms. 

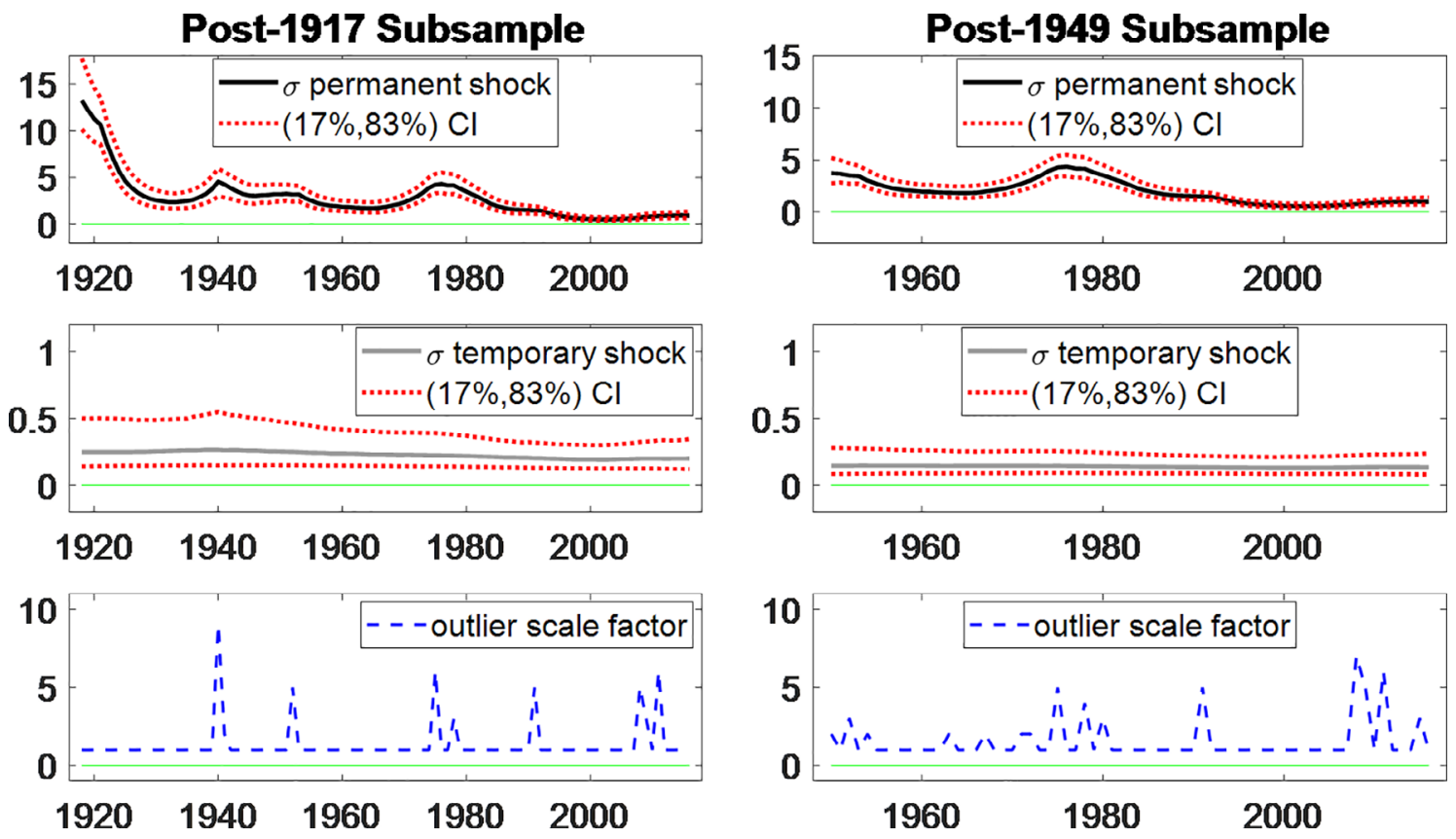

F I G U RE 5 Time-varying volatilities predicted by the UCSVO model. " $\sigma$ permanent shock" is the volatility of changes in the permanent component of inflation, and " $\sigma$ transitory shock" is the volatility of changes in the transitory component. After an initial burn-in phase of 10,000 iterations, the results are based on 50,000 replications, saving every 10 draws [Colour figure can be viewed at wileyonlinelibrary.com]

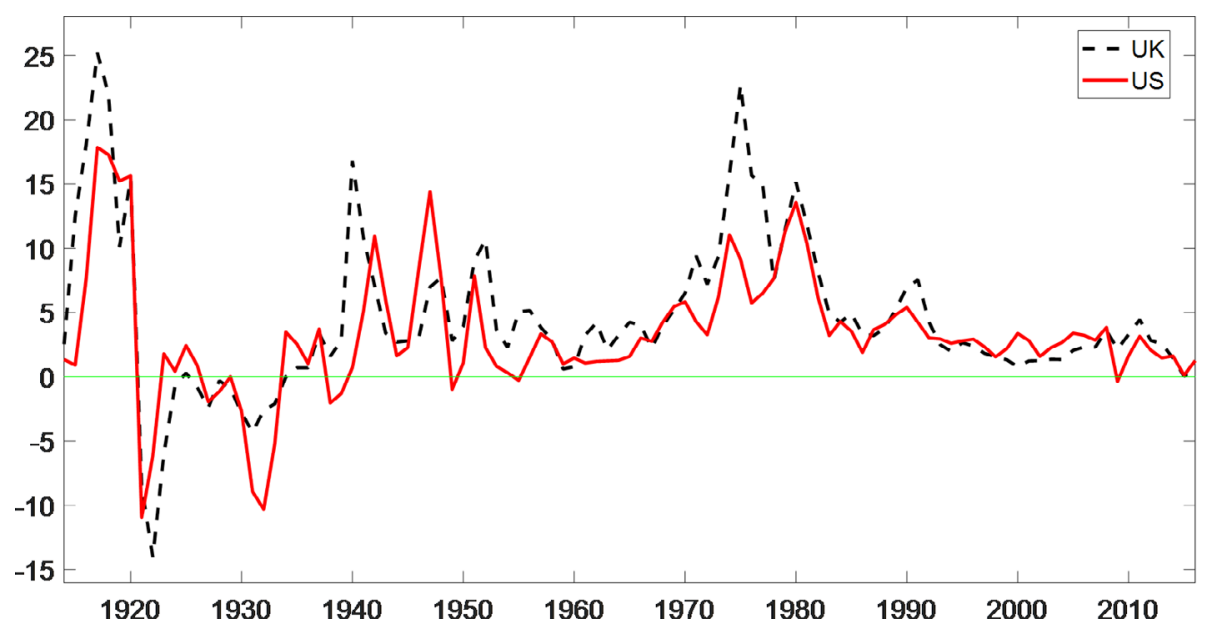

F I G U RE 6 Headline inflation in the UK and US [Colour figure can be viewed at wileyonlinelibrary.com]

T A BLE 7 Summary statistics for the UK and US from the 20th century onward

\begin{tabular}{|c|c|c|c|c|c|c|c|c|}
\hline & \multicolumn{2}{|c|}{ Interward period } & \multicolumn{2}{|c|}{ Bretton woods } & \multicolumn{2}{|c|}{ Bretton woods to inflation targeting } & \multicolumn{2}{|c|}{ Inflation targeting } \\
\hline Mean & -1.89 & -1.80 & 4.37 & 3.13 & 9.18 & 6.30 & 2.09 & 2.30 \\
\hline$S D$ & 4.12 & 4.54 & 2.49 & 3.28 & 5.33 & 3.20 & 1.07 & 1.01 \\
\hline
\end{tabular}

Note: The entries are expressed as percentages. The historical breakdown is as follows: interwar period from 1921 to 1939 , Bretton Woods from 1944 to 1971, Bretton Woods to inflation targeting from 1972 to 1991, inflation targeting from 1992 onwards. 

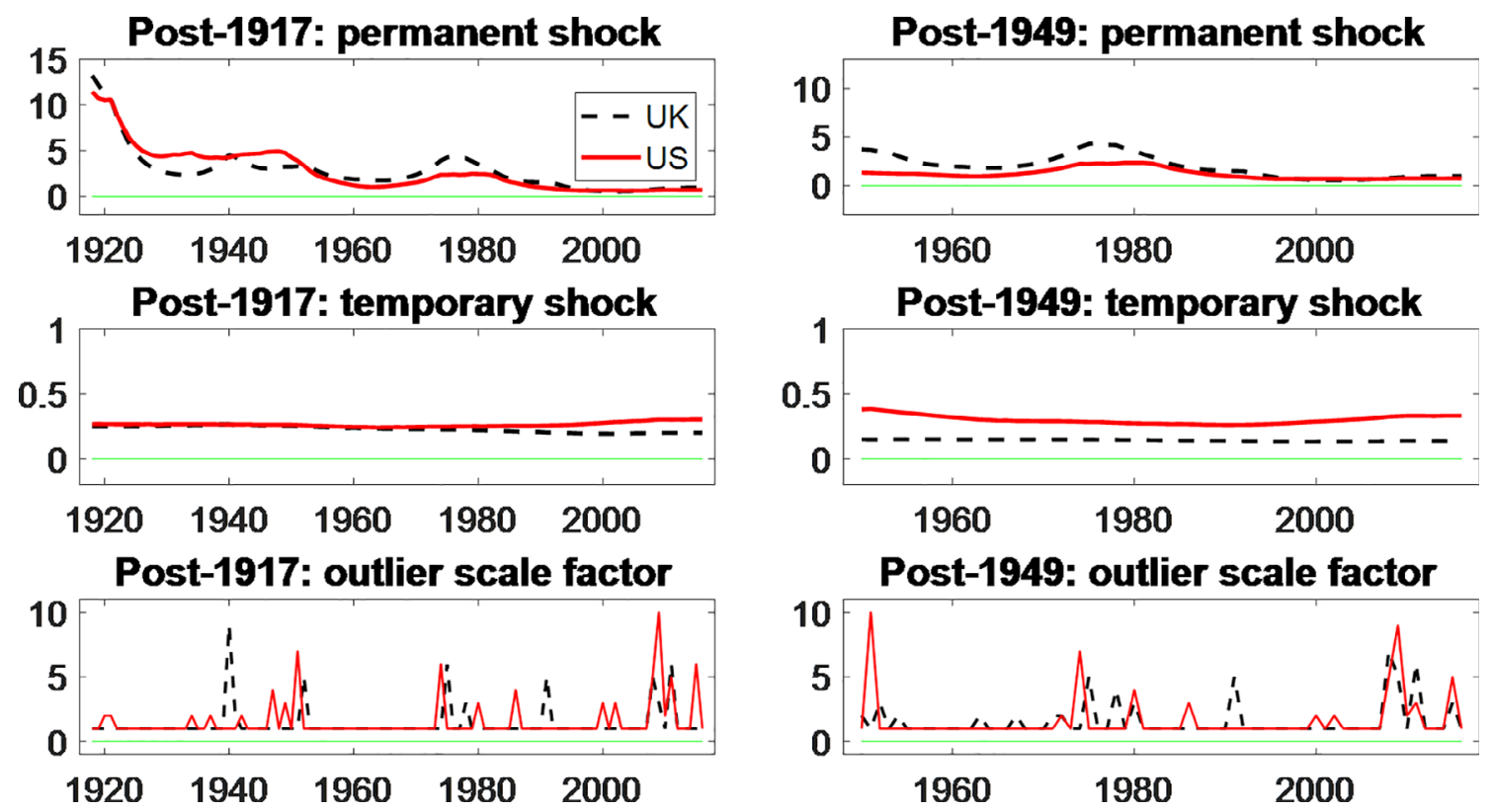

FI G U RE 7 UCSVO results for the UK and US [Colour figure can be viewed at wileyonlinelibrary.com]

two large inflationary spikes that affected the UK in the early 1970s and at the end of the 1980s. This situation was reserved by the adoption of inflation targeting, which led to a lower rate in the UK compared to the US.

The UCSVO results for US inflation are shown in Figure 7, which, similarly to Figure 5, displays the estimated volatility of permanent and transitory shocks and the estimated outliers. ${ }^{12}$ To make the comparison easier, we drop the error bands for both countries. It can be seen that the volatility of permanent shocks was greater in the US than in the UK during the interwar period and WWII, whereas the opposite was true in the 1970s-80s. Indeed, the US was hit hard by the Great Depression of the 1930s, while, as previously mentioned, the UK experienced particularly large inflationary spikes during the energy and oil crises of the 1970s. Nevertheless, the volatility of permanent shock has declined over time in both the UK and US, and it has been roughly equal since the 1990s. Further, the volatility of temporary shocks has remained constant over time for both countries, and has been very similar especially until the end of the 1970s. Finally, there are more frequent outliers for the US than for the UK, especially in the period from the year 1950 onward.

On the whole, there are substantial similarities between UK and US inflation, with the major differences being associated to specific episodes. In particular, the effects of energy and oil shocks were felt first in the UK inflation and only later, during the Great Recession, in the US: there was a greater decline in the variance of permanent shocks during the 1980s in the UK than in the US and a more noticeable clustering of outliers in the US compared to the UK in last 15 years. These changes, rather than persistence, appear to have been the main drivers of inflation since the 1970s in these two countries.

\section{6 | CONCLUSIONS}

This paper uses historical data spanning the period from 1660 to 2016 to examine the degree of persistence in UK inflation. We use long-range dependence (parametric and non-parametric) techniques, more specifically fractional integration models that are more general than those based on the classical I(0) vs. I(1) dichotomy found in most studies and provide more accurate estimates of persistence. In addition, we carry out break tests to detect any shifts in the degree of persistence and also run rolling-window and recursive regressions to examine its evolution over time. Finally, we estimate a UCSVO model to distinguish between permanent and transitory shocks to inflation.

On the whole, the evidence suggests that UK inflation can be characterized as a long-memory stationary process with a relatively stable degree of persistence in the period following the Bretton Woods period, despite the adoption of different monetary regimes. In particular, there is no clear evidence that inflation targeting has brought about a lower degree of inflation persistence, contrary to what claimed in other studies, such as Osborn and Sensier (2009); the fact that these and related studies are based on relatively standard ARMA models and analyse a much shorter time series might account for the different findings. The UCSVO estimates suggest that inflation targeting might have reduced to some extent the impact of permanent shocks on inflation; however, it is their 
lower volatility as well as the presence of some sizeable outliers that appear to account for the break detected in the early 1980s. The same type of analysis carried out for US inflation for comparison purposes leads to broadly similar conclusions.

Future work will aim to investigate possible non-linearities, for instance applying the method of Gil-Alana and Cuestas (2016) based on Chebyshev polynomials in time. Other non-linear approximations can also be incorporated into the $\mathrm{I}(\mathrm{d})$ framework for analysing inflation persistence.

\section{ACKNOWLEGEMENTS}

Luis Alberiko Gil-Alana and Tommaso Trani gratefully acknowledge the financial support received from the Ministerio de Economía y Competitividad: (ECO2017-85503-R) (Luis A. Gil-Alana) and ECO2015-68815-P (Tommaso Trani). We are grateful to an anonymous referee for their helpful comments

\section{DATA AVAILABILITY STATEMENT}

The data that support the findings of this study are available from the authors upon reasonable request.

\section{ORCID}

Guglielmo Maria Caporale (10) https://orcid.org/0000-00020144-4135

Luis Alberiko Gil-Alana (D) https://orcid.org/0000-00025760-3123

\section{ENDNOTES}

${ }^{1}$ More specifically, their study focuses on the inflation gap (the deviations from trend inflation), which is the variable also examined by Cogley, Primiceri, and Sargent (2010). In contrast, as much of the literature, we analyse inflation itself, although the UCSVO estimation also enables us to distinguish the stochastic trend and the transitory inflationary shocks.

${ }^{2}$ Stock and Watson (2007) use a different method to adjust for possible outliers that requires knowing in advance whether large inflationary spikes are mean-reverting.

${ }^{3}$ Note, however, that Benati (2008) found reduced-form evidence that US inflation was highly persistent after the Volcker stabilisation period, a result that is consistent with those of both Cogley and Sargent (2002) and Pivetta and Reis (2007).

${ }^{4}$ The model of Bloomfield (1973) is a simple (non-parametric) approach that approximates highly parameterised ARMA models and is highly suitable in the context of fractional integration (see, for example, Gil-Alana, 2004).

${ }^{5}$ It is nonstationary in the sense that the variance of the partial sums increase in magnitude with $d$.

${ }^{6}$ Very similar results were obtained when using other approaches (Sowell, 1992; Beran, 1995; Lobato and Lobato, 2007). The reason for choosing the method of Robinson (1994) is that it is the most efficient in the Pitman sense against local departures, and, unlike the other methods, it remains valid even in nonstationary contexts $(d \geq 0.5)$.

7 "A millennium of macroeconomic data", version 3.1.

${ }^{8}$ This is a common finding for macro series in the case of autocorrelated disturbances and is attributable to the competition between the fractional differencing parameter and that associated with the autocorrelation structure in accounting for the degree of dependence in the data (see, for example, Gil-Alana \& Robinson, 1997)

${ }^{9}$ Using other window lengths (such as 80 and 100 observations) produced almost identical results.

${ }^{10}$ This frequency of outliers is chosen on the basis of the annual frequency of the data to capture the inflationary spikes that characterised the interwar period, the WWII, the 1970s and the Great Recession. The same criterion is used for the 1950-2016 subsample.

${ }^{11}$ Since the frequency of this time series is monthly, we averaged the observations over the year.

12 The only difference is that, whilst outliers are still assumed to occur every two years in the 1918-2016 period, the assumption for the 1950-2016 period is that they occur every four years in order not to estimate more and larger outliers than those for the period 1918-2016.

${ }^{13}$ Note that nevertheless our assumption produces very similar results to those of Stock and Watson (2016 - see Section B3 in this appendix).

${ }^{14}$ See Stock and Watson (2016) for the specific sequence of steps. We partition the vector of variables for which we need to obtain posterior distributions in the same way as these authors.

\section{REFERENCES}

Altissimo, F., Ehrmann, M., \& Smets, F. (2006). Inflation persistence and price-setting behaviour in the euro area: A summary of the inflation persistence network evidence. Belgium: National Bank of Belgium.

Arghyrou, M., Martin, C., \& Milas, C. (2005). Non-linear inflation dynamics: Evidence from the UK. Oxford Economics Papers, 57 (1), 51-69.

Backus, D.K. and S.E. Zin, 1993, Long-memory inflation uncertainty: Evidence from the term structure of interest rates. NBER Technical Working Paper No. 133.

Bai, J., \& Perron, P. (2003). Computation and analysis of multiple structural change models. Journal of Applied Econometrics, 18(1), 1-22.

Balke, N. S., \& Fomby, T. B. (1997). Threshold cointegration. International Economic Review, 38(3), 627-645.

Baum, C. F., Barkoulas, J. T., \& Caglayan, M. (1999). Persistence in international inflation rates. Southern Economic Journal, 65(4), 900-913.

Benati, L. (2008). Investigating inflation persistence across monetary regimes. The Quarterly Journal of Economics, 123(3), 1005-1060.

Beran, J. (1995). Maximum likelihood estimation of the differencing parameter for invertible short and long memory ARIMA models. Journal of the Royal Statistical Society, Series B, 57, 659-672.

Bloomfield, P. (1973). An exponential model in the spectrum of a scalar time series. Biometrika, 60(2), 217-226. 
Caporin, M., \& Gupta, R. (2017). Dynamics of inflation persistence in international inflation rates. Empirical Economics, 53, 423-439.

Christiano, L., Eichenbaum, M., \& Evans, C. (2005). Nominal rigidities and the dynamic effects of a shock to monetary policy. Journal of Political Economy, 113, 1-45.

Clements, M. P., \& Sensier, M. (2003). Asymmetric output gap effects in Phillips curve and mark-up pricing models: Evidence for the US and the UK. Scottish Journal of Political Economy, 50 (4), 359-374.

Cogley, T., \& Sargent, T. J. (2002). Evolving post-world war II U.S. inflation dynamics. In NBER macroeconomics annual 2001 (Vol. 16, pp. 331-388). Cambridge, Massachusetts: National Bureau of Economic Research.

Cogley, T. W., \& Sbordone, A. M. (2005). A search for a structural Phillips curve. In Staff reports 203. New York, NY: Federal Reserve Bank of New York.

Cogley, T. W., Primiceri, G., \& Sargent, T. J. (2010). Inflation-gap persistence in the US. American Economic Journal: Macroeconomics, 2(1), 43-69.

Dahlhaus, R. (1989). Efficient parameter estimation of self-similar processes. Annals of Statistics, 17, 1749-1766.

Del Negro, M., \& Primiceri, G. E. (2015). Time varying structural vector autoregressions and monetary policy: A corrigendum. Review of Economic Studies, 82(4), 1342-1345.

Dixon, H., and E. Kara, 2006. Understanding inflation persistence: A comparison of different models. European Central Bank working paper series no. 672 .

Gali, J., \& Gertler, M. (1999). Inflation dynamics: A structural econometric analysis. Journal of Monetary Economics, 44(2), 195-222.

Gil-Alana, L. A. (2004). The use of the model of Bloomfield (1973) as an approximation to ARMA processes in the context of fractional integration. Mathematical and Computer Modelling, 39, 429-436.

Gil-Alana, L. A. (2008). Fractional integration and structural breaks at unknown periods of time. Journal of Time Series Analysis, 29, 163-185.

Gil-Alana, L. A., \& Cuestas, J. C. (2016). Testing for long memory in the presence of non-linear deterministic trends with Chebyshev polynomials. Studies in Nonlinear Dynamics and Econometrics, 20(1), 57-74.

Gil-Alana, L. A., \& Robinson, P. M. (1997). Testing of unit roots and other nonstationary hypotheses in macroeconomic time series. Journal of Econometrics, 80, 241-268.

Hassler, U., \& Meller, B. (2014). Detecting multiple breaks in long memory. The case of US inflation. Empirical Economics, 46(2), 653-680.

Hassler, U., \& Wolters, J. (1995). Long memory in inflation rates: International evidence. Journal of Business,Economics and Statistics, 13, 37-45.

Lobato, I. N., \& Lobato, C. (2007). Efficient Wald tests for fractional unit roots. Econometrica, 75(2), 575-589.

Lucas, R., Jr. (1976). Econometric policy evaluation: A critique. Carnegie-Rochester Conference Series on Public Policy, 1(1), 19-46.

Marques, C.R. (2004), Inflation persistence. Facts or artifacts?, European Central Bank, Working paper ECB 371.

Meenagh, D., Minford, P., Nowell, E., Sofat, P., \& Srinivasan, N. (2009). Can the facts of UKinflation persistence be explained by nominal rigidity? Economic Modelling, 26(5), 978-992.

Miles, D. K., Panizza, U., Reis, R., \& Ubide, A. J. (2017). And yet it moves: Inflation and the great recession. In Geneva Reports on the World Economy. London, UK: CEPR Press.
Miles, W., \& Vijverberg, C.-P. (2011). Formal targets, central bank independence and inflation dynamics in the UK: A Markovswitching approach. Journal of Macroeconomics, 33(4), 644-655.

Moreno, R., \& Villar, A. (2010). Inflation expectations, persistence and monetary policy. Monetary policy and the measurement of inflation: prices, wages and expectations, 49, 77-92.

Nelson, E. (2001). What does the UK's monetary policy and inflation experience tell us about the transmission mechanism? In CEPR discussion paper no. 3047. London, UK: CEPR.

Nelson, E. (2009). An overhaul of doctrine: The underpinning of UK inflation targeting. Economic Journal, 119(538), 333-368.

Nelson, E., \& Nikolov, K. (2004). Monetary policy and stagflation in the UK. Journal of Money, Credit and Banking, 36, 293-318.

Okimoto, T., \& Kumar, M. S. (2007). Dynamics of inflation persistence in international inflation rates. Journal of Money, Credit and Banking, 39(6), 1459-1479.

Omori, Y., Chib, S., Shephard, N., \& Nakajima, J. (2007). Stochastic volatility with leverage: Fast and efficient likelihood inference. Journal of Econometrics, 140(2), 425-449.

Osborn, D. R., \& Sensier, M. (2009). UKinflation: Persistence, seasonality and monetary policy. Scottish Journal of Political Economy, 56(1), 24-44.

Pivetta, F., \& Reis, R. (2007). The persistence of inflation in the United States. Journal of Economic Dynamics and Control, 31 (4), 1326-1358.

Rinke, S., Busch, M., \& Leschinski, C. (2017). Long memory, breaks, and trends: On the sources of persistence in inflation rates. In Hannover economic papers (HEP), no 584. Hannover, Germany: Leibniz Universität Hannover, Wirtschaftswissenschaftliche Fakultät.

Robinson, P. M. (1994). Efficient tests of nonstationary hypotheses. Journal of the American Statistical Association, 89, 1420-1437.

Sowell, F. (1992). Maximum likelihood estimation of stationary univariate fractionally integrated time series models. Journal of Econometrics, 53(165), 188.

Stock, J. H., \& Watson, M. W. (2007). Why has U.S. inflation become harder to forecast? Journal of Money, Credit and Banking, 39(S1), 13-33.

Stock, J.H., and M.W. Watson, 2010. "Modeling inflation after the crisis,” NBER Working Papers No. 16488, National Bureau of Economic Research.

Stock, J. H., \& Watson, M. W. (2016). Core inflation and trend inflation. The Review of Economics and Statistics, 98(4), 770-784.

Walsh, C. E. (2007). Optimal economic transparency. International Journal of Central Banking, 3(1), 5-36.

Woodford, M., 2007. "Interpreting Inflation Persistence: Comments on the Conference on "Quantitative Evidence on Price Determination"," Journal of Money, Credit and Banking, 39(s1), 203-210.

How to cite this article: Caporale GM, GilAlana LA, Trani T. On the persistence of UK inflation: A long-range dependence approach. Int J Fin Econ. 2020;1-16. https://doi.org/10.1002/ ijfe.2161 


\section{APPENDIX A.}

i) White noise case

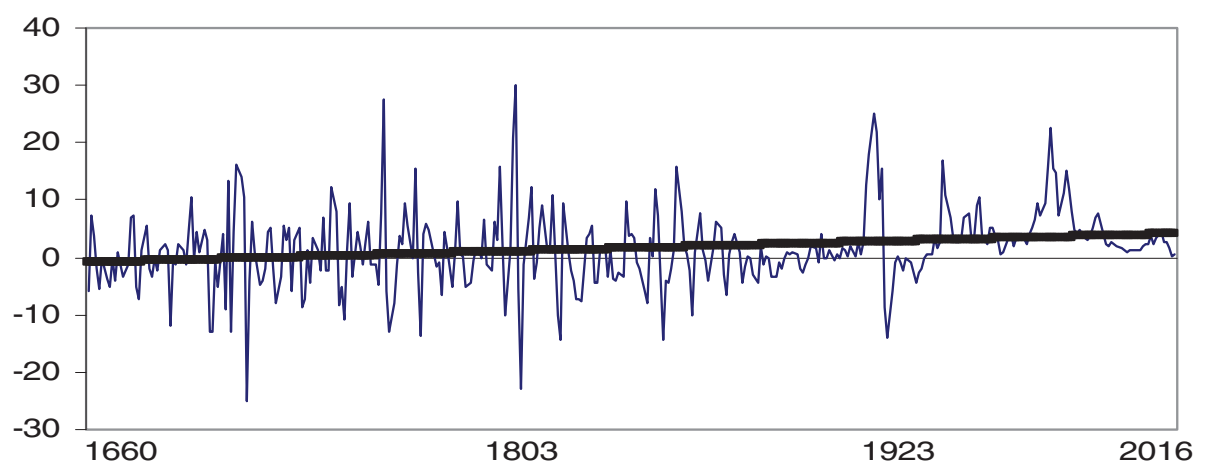

FIGURE A1 UK inflation rate and estimated trends [Colour figure can be viewed at wileyonlinelibrary.com]

ii) Autocorrelation case

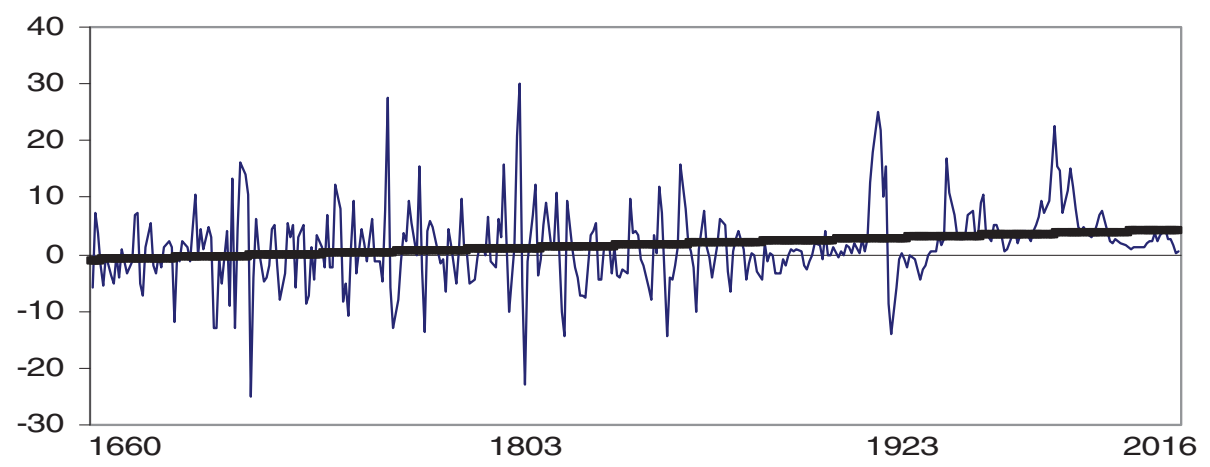

\section{APPENDIX B.}

\section{UCSVO Model}

A UCSVO model (Stock \& Watson, 2016) for trend inflation in the UK is as follows:

$$
\begin{gathered}
y_{t}=\tau_{t}+\varepsilon_{y, t} \\
\tau_{t}=\tau_{t-1}+\sigma_{\Delta \tau, t} \eta_{t} \\
\varepsilon_{y, t}=\sigma_{y, t} S_{t} \zeta_{t}
\end{gathered}
$$

where $y_{t}$ is the observed time series for inflation, $\tau_{t}$ is a martingale trend, $\varepsilon_{y, t}$ is a transitory shock and $\sigma_{y, t}$ is the corresponding volatility, $\sigma_{\Delta \tau, t}$ is the volatility of shocks to the trend, $s_{t}$ is an iid random variable that generates outliers, and, finally, $\eta_{t}$, and $\zeta_{t}$ are idiosyncratic shocks. The two volatilities $\sigma_{y, t}$ and $\sigma_{\Delta \tau, t}$ follow a stochastic process as below:

$$
\Delta \ln \sigma_{y, t}=\gamma_{y} u_{y, t}
$$

$$
\Delta \ln \sigma_{\Delta \tau, t}=\gamma_{\Delta \tau} u_{\Delta \tau, t},
$$

where $u_{y, t}$ and $u_{\Delta \tau, t}$ are random variables so that $\left(\zeta_{t}, \eta_{t}\right.$, $\left.u_{y, t}, u_{\Delta \tau, t}\right)$ is $i i d N\left(0, \mathrm{I}_{4}\right)$.

The assumption embedded in Equation (B3) and (B4) is that transitory shocks are serially uncorrelated and their volatility evolves over time according to a logarithmic random-walk process. Conditional on such a process, transitory shocks are modelled as a mixture of normal distributions through the outlier scale factor $s_{t}$. The distribution generating this outlier scale factor is Bernoulli, so that $s_{t}=1$ with probability $1-p$, and $s_{t}=\mathrm{U}[2,10]$ otherwise. The volatility of permanent shocks also follows a logarithmic random-walk process.

Estimation

We estimate model (B1)-(B5) with Bayesian methods, which require priors for $\gamma_{y}, \gamma_{\Delta \tau}, p, s$ and the initial values of $\tau_{t}, \Delta \ln \sigma_{y, t}$ and $\Delta \ln \sigma_{\Delta \tau, t}$. We set these priors and calibrate the estimation following Stock and Watson (2016), who applied the UCSVO model to US data. Their setup is also suitable for the UK since, as documented by Miles 
FIG URE B1 Trend inflation $\left(\tau_{t}\right)$ predicted by the UCSVO model. This graph displays the mean of the draws of the posterior distributions [Colour figure can be viewed at wileyonlinelibrary.com]
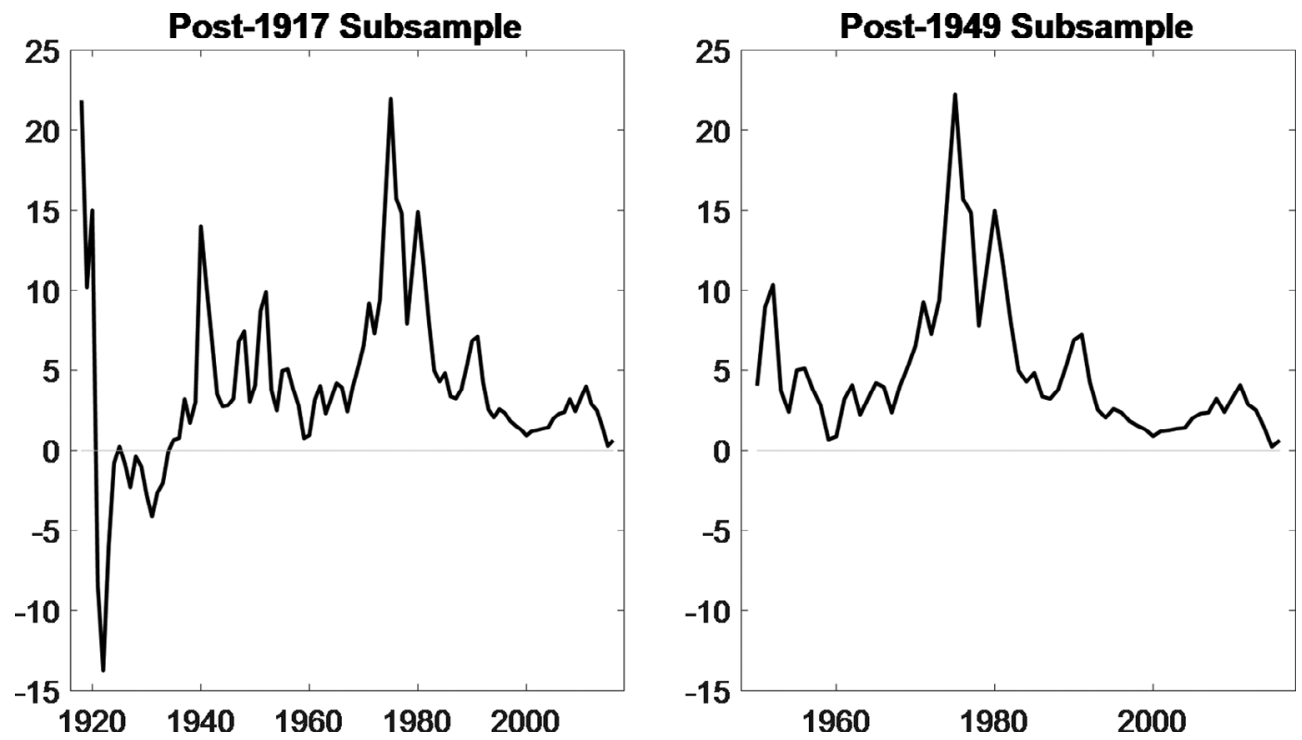

T A B LE B 1 Selected values of the posterior distributions of $\gamma_{y}$ and $\gamma_{\Delta \tau}$

\begin{tabular}{|c|c|c|c|c|c|}
\hline $\begin{array}{l}\text { Value (for } \\
\text { variance) }\end{array}$ & $\begin{array}{l}\text { Prior (for } \\
\text { volatility) }\end{array}$ & \multicolumn{2}{|c|}{ Posterior for $\gamma_{y}$} & \multicolumn{2}{|c|}{ Posterior for $\gamma_{\Delta \tau}$} \\
\hline 0.1 & 0.2 & 0.24 & 0.23 & 0 & 0 \\
\hline 0.2 & 0.2 & 0.21 & 0.21 & 0 & 0.01 \\
\hline 0.4 & 0.2 & 0.13 & 0.15 & 0.95 & 0.8 \\
\hline
\end{tabular}

TAB L E B 2 Posterior distributions of $p$ for a selection of quantiles

\begin{tabular}{lll} 
Quantile & $\begin{array}{l}\text { Posterior for the Post- } \\
\mathbf{1 9 1 7} \text { subsample }\end{array}$ & $\begin{array}{l}\text { Posterior for the Post- } \\
\mathbf{1 9 5 0} \text { subsample }\end{array}$ \\
\hline 0.17 & 0.1 & 0.12 \\
0.5 & 0.15 & 0.19 \\
\hline 0.83 & 0.22 & 0.28 \\
\hline
\end{tabular}

et al. (2017) and by our analysis in Section 5.2.2. However, we make a different assumption about the frequency of outliers compared to Stock and Watson (2016). ${ }^{13}$

The conjugate prior for $p$ is $B(\alpha, \beta)$, and, by assumption, $\alpha$ and $\beta$ reflect information from a subsample of 10 years, with outliers occurring every 2 years. The $\mathrm{U}[2,10]$ prior for the factor $s$ is approximated with an equally spaced grid of nine points. The priors for $\gamma_{y}$ and $\gamma_{\Delta \tau}$ are uninformative uniform priors, and their calibration allows to scale the $S D$ of annual changes in inflation. Given this scaling, $\ln \sigma_{y, t}$, $\ln \sigma_{\Delta \tau, t} \sim \mathrm{U}[0,0.4]$, and we approximate this distribution using equally spaced grids of five points. Finally, the priors for $\tau_{0}, \Delta \ln \sigma_{y, 0}$ and $\Delta \ln \sigma_{\Delta \tau, 0}$ are independent diffuse priors.

The mean and quantiles of the Bayesian posterior distributions are approximated using the MCMC algorithm, whereby $\ln \eta_{t}^{2}, \ln \zeta_{t}^{2} \sim \ln \chi_{t}^{2}$. The approximation of the $\ln \chi_{t}^{2}$ is handled with a mixture of normal distributions, using the 10-component Gaussian mixture of Omori et al. (2007). ${ }^{14}$ The analysis is based on 60,000 iterations, the first 10,000 of which constitute the burn-in phase. Of the remaining 50,000 iterations, we save one every 10 draws.

Additional results

In the paper, we report the posterior distributions for $\sigma_{y, t}, \sigma_{\Delta \tau, t}$ and $s_{t}$ for both the 1918-2016 subsample and the 1950-2016 subsample. In this appendix, we complete the set of results, reporting the posteriors for $\tau_{t}, \gamma_{y}, \gamma_{\Delta \tau}$ and $p$. See Figure B1, Table B1 and Table B2, respectively. 
Furthermore, we repeated the estimation assuming that an outlier can occur every 4 years, while our baseline choice is that outliers occur every 2 years. This choice is justified by the fact that the frequency of our data is annual and WWII, the interwar period, WWII and the 1970s were particularly turbulent times. In particular, for the 1918-2016 period, we assume that outliers can occur every 2 years because, given the fact that we work with annual data, this assumption allows us to capture the inflationary spikes that characterized the interwar period, the WWII, the 1970s and the Great Recession. Turning to the 1950-2016 subsample, we again assume that outliers can occur every 2 years, as this implies that the estimated outlier scale factor is approximately equivalent to the one estimated over the longer sample period. Stock and Watson (2016), who focus on quarterly data for the US over the period from 1960 to mid-2015, assume instead that outliers can occur every 4 years. When we make Stock and Watson's assumption, the MCMC algorithm is unable to predict large inflationary spikes in the 1940s and the 1980s consistently, while this is possible when the prior for $p$ is associated with our baseline case of outliers occurring every two or 3 years. The estimated confidence bands around the median volatility of transitory shocks are slightly smaller in the latter than the former case, but all the other results are very similar. 